\title{
A coexistência da praticabilidade e do direito fundamental à igualdade no controle de preços de transferência sobre juros
}

\section{Coexisting practicability and the fundamental right to equality in Transfer pricing rules on interests}

\author{
Carlos Otávio Ferreira de Almeida* \\ Amanda Salles de Oliveira*
}

\section{Resumo}

O presente trabalho tem como objetivo analisar a constitucionalidade das regras de preços de transferência sobre juros, tomando por base a igualdade e seu corolário, o arm's length, princípio de aceitação internacional. Para tanto, valendo-se do método hipotético-dedutivo, analisa-se criticamente a legislação vigente e respectiva doutrina sobre a matéria. Ao fim, conclui-se que eventual inconstitucionalidade das regras sobre juros, a despeito de não efetivarem a igualdade, depende de análise casuística em vista da coexistência de outros parâmetros garantidos pela Constituição, como a praticabilidade, cujo efeito simplificador objetiva conferir maior eficácia à norma.

Palavras-chave: Arm's Length. Igualdade. Juros. Praticabilidade. Preços de Transferência.

\section{Abstract}

This paper aims to analyze the constitutionality of the Brazilian transfer pricing rules on interests in view of the equality and its equivalent, the arm's length principle. A hypothetical-deductive research was so done, based on reading

Doutor em Direito Econômico, Financeiro, Tributário pela Universidade de São Paulo. Professor Pesquisador - PUC Campinas. Pesquisador Visitante - Vienna University of Economics and Business (WU), Áustria. Doutor em Direito Econômico, Financeiro e Tributário - Universidade de São Paulo USP. Campinas - São Paulo - Brasil. E-mail: carlos.almeida@puccampinas.edu.br

* Advogada. Graduada em Administração - Universidade de São Paulo - USP (Ribeirão Preto). Bacharel em Direito pela Pontifícia Universidade Católica - PUC Campinas. E-mail: amanda. salles@yahoo.com.br 
and critically analyzing the currrent legislation and doctrine. It was concluded that, although the national rules on interests do not ensure the fulfillment of the equality principle, its unconstitutionality shall only be asserted in each single case analysis that considers other constitutional parameters further than isonomy, such as practicability, which through simplification provides higher grade of effectiveness to the norm.

Keywords: Arm's Length. Isonomy. Interests. Transfer Pricing. Practicability.

\section{Introdução}

As últimas décadas foram palco de importantes transformações nas relações econômicas e sociais, através do ingente fenômeno da globalização, que reduziu fronteiras e aumentou, significativamente, fluxo de informações e transferência de bens, direitos e serviços entre países. Essas transformações propiciaram o surgimento de grandes grupos empresariais multinacionais, que, com a instalação de filiais e subsidiárias espalhadas pelo globo, criaram novos modelos de negócio, intensificaram operações comerciais entre países e criaram linhas de produção integradas mundialmente, em atuação, efetivamente, transnacional.

Por conseguinte, intensificaram-se as operações intrafirmas, cujos preços e condições estabelecidos internamente dissociam-se de regras e condições de mercado, mostrando-se, assim, muitas vezes, mais vantajosos.

Nesse contexto, normas sobre preços de transferência surgiram como importante instrumento de controle dos Estados, à medida que visam a combater a evasão de receitas pela alocação dos lucros por entre unidades de um grupo multinacional, conforme interesses empresariais, independente das regras de mercado (ALMEIDA, 2014, p. 300 e 308).

Sobre o assunto, merecem destaque os estudos conduzidos pela Organização para a Cooperação e Desenvolvimento Econômico (OCDE) que consolidaram o arm's length (literalmente, a distância de 
um braço) um importante princípio aplicado à disciplina dos preços de transferência. Basicamente, o arm's length determina que preços e condições praticados nas operações entre pessoas associadas ${ }^{1}$ deverão ser idênticos ou análogos aos praticados nas operações realizadas entre pessoas independentes (OCDE, 2014, p. 15) no mercado aberto.

O arm's length encontra respaldo no princípio da igualdade. Ambos prevêem tratamento desigual a pessoas em situações distintas na medida em que se distinguem o que nem sempre se confirma com relação a regras de preços de transferência sobre juros. Assim, o objetivo do presente estudo é investigar se a regra brasileira de preços de transferência sobre juros desrespeita o princípio constitucional da igualdade; ou, noutro dizer, se seriam tais regras constitucionais em face do indigitado princípio. Esse objetivo é perseguido por meio de pesquisa hipotético-dedutiva (MARCONI, 2002, p. 20), fundamentada na leitura e análise crítica da legislação vigente e da doutrina.

Investigar a juridicidade das regras brasileiras de preços de transferência sobre juros é relevante, pois eventual inconstitucionalidade das normas, além de merecer afastamento, compromete o Estado Democrático de Direito em um de seus pilares, o da justiça. Em contrapartida, se se concluir pela conformação dessas regras ao ordenamento vigente, a pesquisa contribuirá para a observação de outros parâmetros constitucionais que podem coexistir com o princípio da igualdade sem que dessa convivência resulte inconstitucionalidade das normas sob exame.

\footnotetext{
O termo "associadas" ou "associated enterprises" é utilizado pela OCDE para designar os contribuintes que, por atenderem aos quesitos previstos pelo artigo 9 (1) (a) e (1) (b) de sua Convenção Modelo, estão sujeitos às regras de preço de transferência. No original: 1. "Where a) an enterprise of a Contracting State participates directly or indirectly in the management, control or capital of an enterprise of the other Contracting State, or b) the same persons participate directly or indirectly in the management, control or capital of na enterprise of a Contracting State and na enterprise of the other Contracting State [...]". Na legislação dos EUA, já que os ajustes de preços de transferência encontram-se previstos no art. 482 do Código Tributário (Internal Revenue Code), prefere-se o termo "controladas", conforme explicam os EUA, Tax Regulations. $\S 1.482-1(i)(8)$.
} 
De início, apresenta-se o conceito de controle fiscal dos preços de transferência e a aplicação do arm's length nas ordens internacional e interna. Posteriormente, analisa-se a sistemática adotada pelo Brasil para o cálculo dos preços e realização dos ajustes fiscais de operações de remessa ou recebimento de juros. Em seguida, estabelece-se um paralelo do arm's length e sua aplicação na ordem interna através do princípio da igualdade e seu corolário direto, a capacidade contributiva. Por fim, investiga-se a constitucionalidade das regras de preços de transferência sobre juros em face da igualdade tributária, considerandose que a igualdade não deve ser evocada isoladamente, mas em conjunto com outros critérios constitucionais capazes de informar a tributação da renda, de cortar a igualdade segregando situações e pessoas, como a praticabilidade, que mais especialmente servirá de cotejo.

\section{Preços de transferência na ordem internacional}

Transações além-fronteiras, grupos empresariais de atuação transnacional, acelerado desenvolvimento tecnológico e velocidade da informação são efeitos da globalização que levam a possíveis distorções na alocação do capital. É indubitável que a complexidade das operações internacionais dificulta o exato reconhecimento de receitas e despesas, elementos que repercutem, diretamente, na apuração dos tributos incidentes sobre o lucro.

Não raras vezes, operações internacionais submetem-se ao controle fiscal de mais de um Estado, exigindo-se análise sistêmica (e não mais local) de seus impactos. Por conseguinte, problemas práticos como a bitributação da renda, ou a evasão de divisas, através de práticas interempresariais visando à redução da carga tributária, tornam-se correntes.

O tema tem sido destaque na ordem internacional, especialmente por conta dos trabalhos da Organização para Cooperação de Desenvolvimento Econômico (OCDE), que, em seu Relatório Addressing Base Erosion and Profit Shifting Report (2013), destacou a atuação 
crescentemente agressiva das multinacionais no tocante a diversas práticas fiscais, inter alia preços de transferência, instrumentos híbridos, subcapitalização, regimes fiscais privilegiados, cujo efeito principal é o desgaste da base de tributação dos Estados, ou, em outro giro, não recolhimento de tributos (WEEGHEL; EMMERINK, 2013, p. 433).

Nesse cenário, destacam-se as operações entre pessoas vinculadas $^{2}$, cujos preços e condições são definidos internamente, de acordo com os interesses do grupo empresarial. Diferentemente, em observância ao livre mercado, operações independentes são levadas a efeito por pessoas não vinculadas, em que cada um buscará para si as maiores vantagens e a satisfação de seus interesses.

Por conseguinte, preços de transferência podem ser entendidos como aqueles praticados entre pessoas vinculadas em condições distintas das que se verificariam no mercado aberto, ou com pessoa situada em país com tributação favorecida, por ocasião da compra e

Enquanto a OCDE utiliza o termo "associadas" e os EUA, "controladas", para designar os contribuintes sujeitos às regras de preço de transferência, a legislação brasileira traz o conceito de "pessoa vinculada", mais abrangente, previsto pelo artigo 23 da Lei $n^{\circ}$ 9.430/1996. De acordo com esse dispositivo: "[...] será considerada vinculada à pessoa jurídica domiciliada no Brasil: I - a matriz desta, quando domiciliada no exterior; II - a sua filial ou sucursal, domiciliada no exterior; III - a pessoa física ou jurídica, residente ou domiciliada no exterior, cuja participação societária no seu capital social a caracterize como sua controladora ou coligada, na forma definida nos $\S \S 1^{\circ}$ e $2^{\circ}$ do art. 243 da Lei $n^{\circ} 6.404$, de 15 de dezembro de 1976; IV - a pessoa jurídica domiciliada no exterior que seja caracterizada como sua controlada ou coligada, na forma definida nos $\S \S 1^{\circ}$ e $2^{\circ}$ do art. 243 da Lei $n^{\circ} 6.404$, de 15 de dezembro de 1976; V- a pessoa jurídica domiciliada no exterior, quando esta e a empresa domiciliada no Brasil estiverem sob controle societário ou administrativo comum ou quando pelo menos dez por cento do capital social de cada uma pertencer a uma mesma pessoa física ou jurídica; VI - a pessoa física ou jurídica, residente ou domiciliada no exterior, que, em conjunto com a pessoa jurídica domiciliada no Brasil, tiver participação societária no capital social de uma terceira pessoa jurídica, cuja soma as caracterizem como controladoras ou coligadas desta, na forma definida nos $\S \S 1^{\circ} \mathrm{e} 2^{\circ}$ do art. 243 da Lei $n^{\circ} 6.404$, de 15 de dezembro de 1976; VII - a pessoa física ou jurídica, residente ou domiciliada no exterior, que seja sua associada, na forma de consórcio ou condomínio, conforme definido na legislação brasileira, em qualquer empreendimento; VIII - a pessoa física residente no exterior que for parente ou afim até o terceiro grau, cônjuge ou companheiro de qualquer de seus diretores ou de seu sócio ou acionista controlador em participação direta ou indireta; IX - a pessoa física ou jurídica, residente ou domiciliada no exterior, que goze de exclusividade, como seu agente, distribuidor ou concessionário, para a compra e venda de bens, serviços ou direitos; X - a pessoa física ou jurídica, residente ou domiciliada no exterior, em relação à qual a pessoa jurídica domiciliada no Brasil goze de exclusividade, como agente, distribuidora ou concessionária, para a compra e venda de bens, serviços ou direitos." 
venda de bens tangíveis ou intangíveis, serviços, direitos, ou ainda, da remessa ou recebimento de juros nas operações financeiras (HORTA, 2013, p. 284)

Logo, regras de preços de transferência objetivam garantir que operações realizadas entre partes vinculadas, ou com residentes em país com tributação favorecida, apesar das constantes diferenças nos preços e condições praticados, tenham uma tributação isonômica, em observância à capacidade contributiva, na busca por um preço justo, que reflita competitividade (ALMEIDA, 2009, p. 113).

Não por outra razão, o lucro ou prejuízo contábil, ao registrar os resultados dessas operações vinculadas, não seria necessariamente confiável para apuração da renda da empresa, a menos que reflita os preços de mercado (SCHOUERI, 2013, p. 13).

Portanto, tal condição de igualdade seria alcançada mediante ajuste, realizado pelo Estado, dos resultados das operações entre pessoas vinculadas, registrados contabilmente, em face dos que seriam observados caso tais operações tivessem sido praticadas por partes não vinculadas, em condições normais de mercado.

No âmbito dos tratados de bitributação, a adequação dos resultados obtidos nas operações intragrupo está prevista pelo artigo $9^{\circ}$ da Convenção Modelo da OCDE. Por esse dispositivo, sempre que o lucro obtido nas operações comerciais e financeiras entre pessoas associadas for diverso daquele que teria sido obtido se as mesmas operações fossem praticadas por pessoas independentes, e em condições similares, a diferença representada pela parcela do lucro não auferido pela associada poderá ser adicionada ao seu resultado contábil para fins de tributação.

Além da previsão na Convenção Modelo, a OCDE publicou, em 1995, o Transfer Pricing Guidelines for Multinational Enterprises and Tax Administrations, consequência de seus esforços na coordenação dos diversos interesses de seus membros e na busca pelo consenso quanto ao reconhecimento de receitas e despesas, bem como do 
lucro a ser tributado em operações internacionais. O relatório contém recomendações no tocante aos preços de transferência, inclusive a sugestão de métodos a fim de orientar as administrações fiscais e os parceiros comerciais na análise da operação e na determinação dos preços a serem utilizados como parâmetro para realização dos ajustes (OCDE, 2009, p. 27).

Essas diretrizes foram construídas com fundamento no arm'slength, princípio que reflete a necessidade de aproximar preços praticados nas operações entre pessoas associadas daqueles que seriam obtidos se as mesmas operações fossem realizadas por pessoas independentes. Eventuais distorções identificadas a partir da comparação entre essas operações deverão ser adicionadas aos resultados contábeis para fins de tributação.

Nesse contexto, os métodos sugeridos pela OCDE objetivam viabilizar a comparabilidade entre essas operações, auxiliando na identificação de quais preços teriam sido praticados ante a inexistência de qualquer fator vinculante entre as partes.

Logo, o preço arm's length seria aquele obtido em similares condições comerciais e financeiras encontradas por partes independentes em operações comparáveis no mercado aberto. Seria, em outro giro, tratar pessoas vinculadas como se independentes fossem (CURTY, 2013, p. 222). Ora, justamente esse potencial uniformizador quanto a questões afetas aos preços de transferência que justifica a adoção do arm's length pelos membros da OCDE e por número crescente de Estados não membros, já que por meio do separate entity approach trata membros de um grupo multinacional como se fossem empresas independentes (ALMEIDA, 2009, p. 105).

Luís Eduardo Schoueri (2013, p. 37) aponta três principais razões favoráveis à adoção do arm's length, assim resumidas:

i. não haveria melhor forma para alocação dos recursos e compensação pelos esforços senão através das forças de mercado; 
ii. seria uma forma de evitar vantagens tributárias decorrentes da manipulação e concentração do poder econômico de enormes grupos multinacionais (para a OCDE, colocar pessoas associadas em igualdade de condições com pessoas independentes, para fins fiscais, evita a criação de benefícios ou desvantagens que poderiam afetar a competitividade com relação às demais entidades).

iii. Ampla e satisfatória adoção desse princípio por diversos países.

Contudo, a própria OCDE reconhece limitações inerentes aos métodos por ela sugeridos, em decorrência da complexidade ou de peculiaridades inerentes a determinadas operações. Por vezes é difícil, ou até mesmo inviável, estabelecer comparações seguras em face da inexistência de parâmetros similares no mercado (OCDE, 2009, p. 27). É o caso dos ganhos obtidos com escala, ou ainda, da compra e venda de produtos e serviços altamente especializados (SCHOUERI, 2013, p. 38).

Em resposta a essas limitações, a OCDE recomenda que tanto o fisco quanto os contribuintes, ao se depararem com situações que inviabilizem a utilização dos métodos por ela previstos, possam aplicar e mesmo desenvolver outros métodos, ainda que não amplamente conhecidos, desde que se comprove observância do arm's length.

\section{Preços de transferência na ordem interna}

No Brasil, as primeiras disposições legais acerca da determinação dos preços de transferência surgiram com a publicação da Lei $n^{\circ}$ 9.430/96, artigos 18 a 22, onde se abrigam os métodos para análise dos preços de transferência.

Basicamente, tais dispositivos apresentam a metodologia para cálculo do denominado preço parâmetro, que servirá de base para comparação com os preços efetivamente praticados em operações entre pessoas vinculadas ou entre pessoa residente ou domiciliada no Brasil 
com qualquer pessoa residente ou domiciliada em país com tributação favorecida ou beneficiada por regime fiscal privilegiado.

Assim, ao se comparar o preço praticado, efetivamente, nas operações sujeitas a regras de preços de transferência e o preço parâmetro, obtido por um dos métodos legais, eventual diferença deverá ser adicionada ao lucro contábil para determinação do Lucro Real, ou, ainda, aos Lucros Presumido ou Arbitrado, para determinação das bases de cálculo do Imposto de Renda da Pessoa Jurídica (IRPJ) ${ }^{3}$ e da Contribuição Social sobre o Lucro Líquido (CSLL).

Os métodos previstos pela legislação brasileira são segregados entre os aplicáveis às operações de importação e às operações de exportação. Por conseguinte, o preço parâmetro ora será um limite máximo, no caso dos gastos com importação; ora será receita mínima a ser auferida, no caso das operações de exportação.

Assim, quando os preços praticados nas operações de importação forem superiores ao preço parâmetro, evidenciando condições mais vantajosas que o estabelecido como aceitável pelo legislador, a diferença apurada representará parcela não dedutível das despesas incorridas com a operação considerada. Logo, tal parcela deverá ser adicionada ao resultado contábil para fins de determinação da base de cálculo do IRPJ e da CSLL.

De modo similar, quando os preços praticados nas operações de exportação forem inferiores ao parâmetro estabelecido pelos métodos legais, a diferença representada pela receita não registrada deverá

Nos termos do artigo 44 do Código Tributário Nacional, a base de cálculo do imposto de renda pode ser obtida, basicamente, por três diferentes regimes, quais sejam o Lucro Real, o Lucro Presumido ou ainda, o Lucro Arbitrado. Pelo primeiro regime, a base de cálculo do imposto de renda da pessoa jurídica será o Lucro Real, obtido a partir do resultado contábil (lucro líquido ou prejuízo), após a realização de ajustes (adições e exclusões) previstos pela legislação tributária. O Lucro Presumido, por sua vez, é obtido pela aplicação de um percentual prefixado de acordo com a atividade da Sociedade, sobre a receita bruta apurada contabilmente. Nos casos em que o contribuinte não mantiver as escriturações e demonstrações financeiras na forma das leis comerciais e fiscais, ou ainda, optar indevidamente pelo Lucro Presumido, a base de cálculo do imposto de renda poderá ser determinada por arbitramento. Cf. Decreto $n^{\circ} 3.000$, de 26 de março de 1999 (Regulamento do Imposto de Renda), art. 246 e seguintes. 
ser oferecida à tributação através da sua adição ao resultado contábil para determinação do Lucro Real, assim como ser computada para determinação do Lucro Presumido ou Arbitrado e da base de cálculo da CSLL.

Possível, pois, concluir que a legislação dos preços de transferência dispõe acerca da dedutibilidade das despesas ou mesmo da tributação de receitas obtidas nas operações entre vinculadas ou entre residente no Brasil e qualquer pessoa residente em países com tributação favorecida ou regime fiscal privilegiado.

\subsection{Tratamento inicialmente conferido aos juros}

Regras específicas acerca da tributação das receitas e dedutibilidade das despesas com juros decorrentes de operações entre vinculadas estão dispostas no art. 22 da Lei 9.430/96, dispositivo recentemente alterado após críticas e questionamentos por desvio do arm's length.

Para melhor compreensão do assunto, na legislação brasileira são encontrados, basicamente, dois tipos de métodos para determinação do preço parâmetro: (i) comparativos, que buscam no mercado informações de operações idênticas ou similares praticadas entre pessoas não vinculadas; e (ii) presuntivos (margens predeterminadas), que são autossuficientes no sentido de utilizarem apenas elementos extraídos da própria operação com a vinculada, já que o legislador previamente determina uma margem fixa de lucro, independente da realidade (CURTY, 2013, p. 224).

As regras de preços de transferência sobre juros são baseadas nesse último sistema e é justamente da utilização de percentuais presumidos que surgem as principais críticas à legislação nacional, como será demonstrado a seguir.

Em sua redação original, o artigo 22 da Lei $n^{\circ}$ 9.430/1996 previa a aplicação das regras de preços de transferência aos juros pagos ou 
creditados à pessoa vinculada apenas para contratos não registrados no Banco Central do Brasil (BACEN):

Art. 22. Os juros pagos ou creditados a pessoa vinculada, quando decorrentes de contrato não registrado no Banco Central do Brasil, somente serão dedutíveis para fins de determinação do lucro real até o montante que não exceda ao valor calculado com base na taxa Libor, para depósitos em dólares dos Estados Unidos da América pelo prazo de seis meses, acrescida de três por cento anuais a título de spread, proporcionalizados em função do período a que se referirem os juros. (Grifo nosso).

Assim, haveria uma espécie de safe harbour para os contratos registrados que estariam sujeitos, por força do artigo $8^{\circ}$ da Lei $n^{\circ} 4.131 / 1962$, apenas ao controle realizado pelo BACEN, órgão competente para impugnar ou mesmo rejeitar contratos com previsão de taxas de juros discrepantes das vigentes no mercado (HORTA, 2013, p.286), dispensando-se os contribuintes da comprovação dos preços de transferência.

Por sua vez, contratos não registrados junto ao BACEN sujeitarse-iam ao controle dos preços de transferência sob o parâmetro estabelecido pela aplicação da taxa London Interbank Offered Rate (LIBOR), para depósitos em dólares dos Estados Unidos da América pelo prazo de seis meses, acrescida de três por cento anuais a título de spread, proporcionalizados em função do período a que se referirem os juros.

O cálculo deveria ser efetuado sobre o valor da operação expresso no contrato e, posteriormente, convertido para moeda local, conforme taxa de câmbio divulgada pelo BACEN para data do termo final do cálculo dos juros.

Com isso, nos casos em que o contribuinte nacional figurava como mutuário, a dedutibilidade das despesas com juros estava condicionada ao limite máximo previsto pelo método descrito no caput do artigo 22 da Lei $n^{\circ} 9.430 / 96$. Eventual excesso seria somado ao lucro ou prejuízo 
contábil para fins de determinação da base de cálculo do IRPJ e da CSLL.

Por sua vez, para operações em que o mutuante situava-se no Brasil, o mesmo cálculo representaria parâmetros mínimos, ou seja, a receita mínima que deveria ser obtida a título de juros com a operação. Logo, no caso de registro de receita financeira inferior ao estabelecido como parâmetro, a diferença resultaria no ajuste oferecido à tributação.

Críticas, então, ecoaram sobre a opção do legislador por um parâmetro prefixado para cálculo dos limites máximo e mínimo na sistemática dos juros. A fixação de margens, sem qualquer comparação com dados disponíveis no mercado acerca de operações idênticas ou similares, praticadas entre pessoas não vinculadas, contribuía para o distanciamento do arm's length, norteador do controle dos preços de transferência (BIFANO, 2013, p. 107).

Tampouco estaria em consonância com o arm's length a utilização da taxa Libor para depósitos em dólares dos Estados Unidos da América pelo prazo de seis meses sem se considerar a duração da operação prevista no contrato. Isso demonstra que as regras estabelecidas negligenciavam práticas comuns de mercado, como as realizadas entre pessoas não vinculadas em que os juros poderiam ser baixos ou inexistentes com o fito de desenvolver novos mercados ou outros interesses negociais (SCHOUERI, 2013, p. 344).

Por se afastar do princípio arm's length, essa sistemática permitia a criação de uma renda presumida, distinta do conceito de renda sobre o qual recai a autorização constitucional para incidência tributária. Logo, o ajuste gerado deixava de representar renda efetivamente produzida, que apenas não fora reconhecida contabilmente devido a distorções geradas pelos preços e condições negociais em operações entre vinculadas, para representar a tributação de uma renda mínima, ainda que inexistente.

A flexibilização das margens, em circunstâncias especiais, por meio de pedido ao Ministro da Fazenda não socorria à regra dos 
juros, pois se restringia às margens ditadas pelos artigos 18 e 19, não contemplando o art. 22 da Lei 9.430/96. ${ }^{4}$ Uma vez demonstrada a incompatibilidade entre o preço parâmetro e os preços normais de mercado em operação similar, poderia o contribuinte pleitear, mediante processo administrativo, a alteração das margens prefixadas por outras que considerasse mais justas às suas transações. ${ }^{5}$

2.2 Alteração da disciplina dos preços de transferência sobre juros

Em 2012, a legislação pertinente aos preços de transferência sofreu duas importantes alterações com as publicações da Lei n 12.715 , aos 17 de setembro, e da Lei $n^{\circ} 12.766$, aos 27 de dezembro, trazendo nova disciplina referente aos juros.

As primeiras alterações foram veiculadas pela Medida Provisória $\mathrm{n}^{\circ} 563$, de 3 de abril de 2012, posteriormente convertida na Lei $\mathrm{n}^{\circ}$ $12.715 / 2012$, que eliminou o safe harbour previsto até então no caput e no parágrafo $4^{\circ}$ do artigo 22 , de modo que o controle fiscal dos preços de transferência fosse distendido para abranger a generalidade dos contratos, ainda que registrados junto ao Banco Central do Brasil (PELÁ, 2013, p.9).

Outra alteração trazida pela Lei $n^{\circ} 12.715 / 2012$, ainda no caput do artigo 22, diz com a natureza dos contratos, que deveriam ser de mútuo. A inclusão dessa condição seria uma restrição à legislação original, de modo que as regras não mais se aplicariam a todo e qualquer contrato, mas tão só aos relacionados às operações de mútuo entre empresas vinculadas.

Cf. artigo 20 da Lei n 9.430/1996 e, posteriormente, a Portaria do Ministério da Fazenda $n^{\circ} 222$ de 24 de setembro de 2008.

5 "Art. 20. Em circunstâncias especiais, o Ministro de Estado da Fazenda poderá alterar os percentuais de que tratam os arts. 18 e 19, caput, e incisos II, III e IV de seu $\S 3^{\circ}$." Como juros são tratados pelo art. 22 da referida Lei, não estariam cobertos por esta previsão. 
Os novos dispositivos teriam vigência a partir de $1^{\circ}$ de janeiro de 2013, muito embora dúvidas surgissem quanto aos contratos firmados anteriormente a essa data, com previsão de incidência e remessas de juros para períodos subsequentes.

Antes, porém, da vigência desses novos dispositivos, veio a lume a Lei $n^{\circ} 12.766 / 2012$, regulamentada pela Instrução Normativa da Receita Federal do Brasil (IN/RFB) $n^{0} 1.312$, de 28 de dezembro de 2012, trazendo nova redação ao artigo 22 da Lei $n^{\circ}$ 9.430/96. O objetivo da nova lei era reduzir o distanciamento observado entre os limites legais até então estabelecidos com relação às taxas efetivamente praticadas nas operações no mercado aberto.

A nova lei manteve o alcance das regras de preços de transferência sobre todos os contratos firmados a partir de $1^{\circ}$ de janeiro de 2013, independente do registro junto ao BACEN, como já previsto pela Lei $n^{\circ} 12.715 / 2012$. Aos contratos celebrados antes dessa data, porém, permanecia aplicável a legislação anterior, Lei $n^{\circ}$ 9.430/1996, incluindo a salvaguarda para os contratos registrados no BACEN.

Que regra, no entanto, aplicar a contratos celebrados até 31/12/2012 com previsão de remessa ou reconhecimento de juros em períodos posteriores? A resposta veio com a edição da IN/RFB n 1.322, de 16 de janeiro de 2013, que alterou o caput do artigo 58 da IN/RFB $\mathrm{n}^{\circ} 1.312 / 2012$ e confirmou o procedimento previsto pelo $\S 9^{\circ}$ do artigo 22 da Lei $n^{\circ}$ 9.430/1996, incluído pela Lei $n^{\circ} 12.766 / 2012$. Assim, a regra aplicável, bem como a taxa e o spread, para cálculo dos limites a serem pagos ou creditados à pessoa vinculada, a título de juros, deve ocorrer no momento da contratação da operação. Uma vez definidos, esses percentuais serão aplicados enquanto vigorar o contrato, que se imuniza quanto a possíveis alterações nas taxas praticadas no mercado independente de beneficiar ou não o contribuinte e dispensa a necessidade de revisões periódicas (RODRIGUEZ, 2013, p. 234).

No contexto das novas regras, a novação e a repactuação são tidas por novos contratos (art. 22, §10, Lei n 9.430/96). Logo, a partir de 2013 , verificada alguma dessas alterações contratuais, as operações 
correspondentes estarão submetidas às novas regras de preços de transferência sobre juros (PELÁ, 2013, p.15).

Outra inovação foi a eliminação, no caput do artigo 22, dos termos "contrato", previsto pela redação original da Lei n 9.430/1996, e "contrato de mútuo", restrição trazida pela redação da Lei $n^{\circ} 12.715 / 2012$. A eliminação desses termos ampliou o campo de operações sujeitas ao controle fiscal dos juros em matéria de preços de transferência.

Doravante, portanto, não somente operações entre vinculadas firmadas mediante contrato ou contrato de mútuo serão alcançadas pela lei, mas toda e qualquer operação em que seja entregue capital ou investimento para retorno posterior por meio de juros ou remuneração, independentemente do instrumento utilizado (HORTA, 2013, p. 290).

No tocante aos percentuais aplicáveis para cálculo dos limites e eventuais ajustes foram inseridas as mudanças mais expressivas pelo legislador, na tentativa de aproximar as taxas consideradas aceitáveis para fins de controles fiscais com relação às praticadas no mercado aberto. Anteriormente, o cálculo dos limites tinha por base o percentual a título de spread até então fixado em 3\% ao ano e proporcionalizados pelo período a que se referissem os juros; e a taxa LIBOR, para depósitos em dólares dos EUA, pelo prazo de seis meses.

Com relação ao spread, o legislador abandonou o percentual fixo de $3 \%$, incumbindo o Ministro da Fazenda a definir, com base na média de mercado, a margem percentual a título de spread, para o que dispõe de informações calculadas e divulgadas pelo BACEN relativas ao spread médio praticado no mercado. Eventualmente, delas poderá se afastar, mas em vista de outro critério justificador da margem estabelecida (BIFANO, 2013, p.114).

As taxas de juros, fixadas pelo legislador, variam conforme a moeda em que se realizar a operação, nos termos do artigo 22 da Lei $n^{\circ}$ 9.430/1996, verbis:

§ 6 A taxa de que trata o caput será a taxa:

I- de mercado dos títulos soberanos da República Federativa 
do Brasil emitidos no mercado externo em dólares dos Estados Unidos da América, na hipótese de operações em dólares dos Estados Unidos da América com taxa prefixada; II - de mercado dos títulos soberanos da República Federativa do Brasil emitidos no mercado externo em reais, na hipótese de operações em reais no exterior com taxa prefixada; e

III - London Interbank Offered Rate - LIBOR pelo prazo de 6 (seis) meses, nos demais casos.

$\S 7^{\circ} \mathrm{O}$ Ministro de Estado da Fazenda poderá fixar a taxa de que trata o caput na hipótese de operações em reais no exterior com taxa flutuante.

Louvável o esforço do legislador em abandonar a manutenção de apenas uma taxa, a LIBOR, como parâmetro aplicado a todas as operações, bem como de um spread fixo e inconsistente com um mercado dinâmico e mutável (SANTOS, 2013, p. 164).

O quadro a seguir apresenta a síntese das principais alterações na legislação concernente ao preço de transferência sobre juros, abordadas neste capítulo: 


\section{Quadro 1 - Alterações na legislação de preços de transferência sobre juros}

\begin{tabular}{|c|c|c|c|}
\hline & Lei no 9.430/1996 & Lei $n^{\circ} 12.715 / 2012$ & Lei $n^{0} 12.766 / 2012$ \\
\hline Produção de efeitos & $\begin{array}{c}\text { Operações } \\
\text { registradas a partir } \\
\text { de } 1^{\circ} \text { de janeiro de } \\
2007\end{array}$ & \begin{tabular}{|c|} 
Previsto para \\
contratos celebrados \\
a partir de $1^{\circ}$ de \\
janeiro de 2013 \\
(nunca produziu \\
efeitos) \\
\end{tabular} & $\begin{array}{c}\text { Contratos celebrados a partir de } 1^{\circ} \text { de } \\
\text { janeiro de } 2013\end{array}$ \\
\hline Operações sujeitas & $\begin{array}{c}\text { Os juros pagos ou } \\
\text { creditados a pessoa } \\
\text { vinculada. }\end{array}$ & $\begin{array}{c}\text { Os juros pagos ou } \\
\text { creditados a pessoa } \\
\text { vinculada, quando } \\
\text { decorrentes de } \\
\text { contrato de mútuo. }\end{array}$ & $\begin{array}{l}\text { Os juros pagos ou creditados a pessoa } \\
\text { vinculada. }\end{array}$ \\
\hline Salvaguarda & $\begin{array}{c}\text { Contratos registrados } \\
\text { no BACEN }\end{array}$ & Não há & Não há \\
\hline $\begin{array}{l}\text { Percentuais para cálculo do } \\
\text { limite de dedutibilidade e da } \\
\text { receita mínima a ser apurada }\end{array}$ & $\begin{array}{c}\text { Taxa Libor (para } \\
\text { depósitos em dólares } \\
\text { dos Estados Unidos } \\
\text { da América pelo } \\
\text { prazo de seis meses) } \\
\text { mais 3\% a.a. à título } \\
\text { de spread. }\end{array}$ & $\begin{array}{c}\text { Taxa Libor (para } \\
\text { depósitos em dólares } \\
\text { dos Estados Unidos } \\
\text { da América pelo } \\
\text { prazo de seis meses) } \\
\text { mais } 3 \% \text { a.a. à título } \\
\text { de spread. } \\
\text { *O Ministro de } \\
\text { Estado da Fazenda } \\
\text { poderá reduzir o } \\
\text { percentual de spread, } \\
\text { bem como } \\
\text { restabelecê-lo até o } \\
\text { valor fixado de } 3 \% .\end{array}$ & 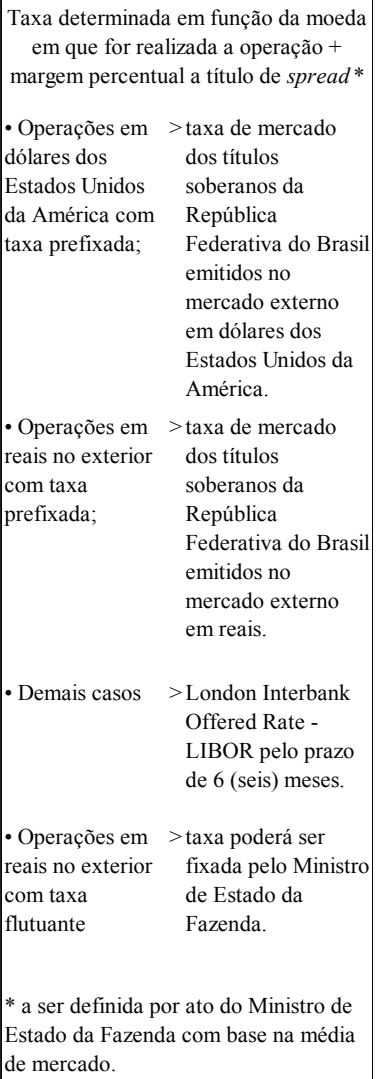 \\
\hline
\end{tabular}




\section{Coexistência da igualdade e da praticabilidade no controle de preços de transferência sobre juros}

\subsection{Aplicação do princípio arm's length}

A Exposição de Motivos da Lei n 9.430/1996, que introduziu o controle dos preços de transferência no País, referenciou as diretrizes estabelecidas pela OCDE como base para as normas brasileiras, a despeito de o Brasil não ser membro daquela organização internacional. ${ }^{6}$

Inobstante as diretrizes sobre preços de transferência da OCDE consagrarem o arm's length, princípio de ampla aceitação internacional, o legislador brasileiro não o acolheu de forma expressa. A ausência do registro gráfico, todavia, não deve fazer crer que o arm's length não tenha sido recepcionado entre nós, pois sua aplicação pode ser evidenciada por intermédio do princípio da igualdade (SCHOUERI, 2013, p. 14).

A igualdade aparece inicialmente no texto constitucional de modo genérico, como norteadora dos demais princípios e garantias previstos pelo artigo $5^{\circ}$ da Carta Magna. Posteriormente, tal princípio é evocado pelo artigo 150, II, como parâmetro limitador do poder de tributar do Estado, no que representa importante meio de proteção ao contribuinte.

Basicamente, oferecer o mesmo tratamento a todos, indistintamente, ignorando dessemelhanças, ofende a igualdade. Portanto, a desigualdade serve de calibração para garantir tratamento isonômico a indivíduos em condições díspares. Diferençar contribuintes,

6 Cf. Exposição de Motivos n 470, de 15 de Outubro de 1996: "12. As normas contidas nos arts. 18 a 24 representam significativo avanço da legislação nacional face ao ingente processo de globalização, experimentado pelas economias contemporâneas. No caso especifico, em conformidade com regras adotadas nos países integrantes da OCDE, são propostas normas que possibilitam o controle dos denominados "Preços de Transferência" de forma a evitar a prática, lesiva aos interesses nacionais, de transferências de resultados para o exterior, mediante a manipulação dos preços pactuados nas importações ou exportações de bens, serviços ou direitos, em operações com pessoas vinculadas, residentes ou domiciliadas no exterior". Diário da Câmara dos Deputados, ano LI, n 214. Brasília, DF, 19 de novembro de 1996. Disponível em: <http://imagem.camara.gov.br/Imagem/d/pdf/DCD19NOV1996.pdf\#page=43>. Acesso em: 16 mar. 2015. 
no entanto, exige a fixação prévia de critérios capazes de franquear a nítida discriminação dos elementos integrantes de determinado objeto de análise. Não por outra razão, a igualdade deve ser relativizada, conforme prévios critérios discriminatórios (SCHOUERI, 2013, p. 14-17).

Com efeito, a igualdade tributária significa, sobretudo, proibição de arbitrariedade, de excesso ou de desproporcionalidade. Não se veda toda e qualquer desigualdade, já que esta pode se justificar ante critérios constitucionais; mas antes, de coibir desigualdades arbitrárias, sem fundamento em qualquer princípio constitucional (TORRES, 1999, p. 327).

O controle de preços de transferência baseia-se na comparabilidade e, por meio do arm's length, confere ampla paridade no trato fiscal dispensado a grupos multinacionais e a empresas independentes, o que evita distorções num cenário competitivo baseado no tipo de empresa. Portanto, o arm's length consolida o tratamento isonômico a operações intragrupo tomando por base operações reais de mercado praticadas por empresas independentes.

O primeiro critério comparativo, em matéria de tributação da renda, é a capacidade contributiva, corolário direto do princípio da igualdade, conforme se verá a seguir.

\subsection{Igualdade e capacidade contributiva}

A igualdade tributária deve ser analisada como princípio vazio, objeto de ponderação com outros princípios constitucionais, com base em critérios previamente determinados pelo legislador a fim de coibir eventuais arbitrariedades, dentre os quais, a capacidade contributiva (SCHOUERI, 2013, p. 16).

A capacidade contributiva reflete a igualdade horizontal, cujo alcance, no âmbito da tributação da renda, se dá quando duas pessoas que auferem as mesmas rendas, em condições semelhantes, suportam o mesmo ônus a título de imposto. Insculpida no art. $145, \S 1^{\circ}$ do Texto 
Maior, ${ }^{7}$ a capacidade contributiva transporta a carga de valor e de coerência necessária à comparação de que a igualdade se utiliza para configurar-se como um dos mais fortes pilares do Estado Democrático de Direito (ALMEIDA, 2009, p. 115).

Neste passo, não haverá igualdade se a comparação mostrarse inviável por envolver situações econômicas distintas. Enquanto um contribuinte concorre no mercado aberto, outro transaciona com empresa do mesmo grupo. Logo, a comparação envolvendo operações entre pessoas vinculadas exige a conversão prévia dos valores registrados intragrupo para os valores de mercado, registrados em operações similares praticadas por pessoas independentes, papel este de que bem se desincumbe o arm's length (SCHOUERI, 2013, p. 16).

O controle dos preços de transferência, portanto, atende a um imperativo constitucional, buscando aplicar tratamento isonômico a pessoas vinculadas e pessoas independentes, tornando possível a comparação de unidades de referência próprias de um grupo (intrafirmas) com unidades geralmente menos vantajosas, obtidas no mercado aberto (reais de mercado).

No entanto, dado o volume e complexidade das operações sujeitas a esse controle, a busca por valores de mercado pode ser árida e inócua, frustrando o ajuste dos valores registrados nas operações intrafirmas para refletirem realidade similar. Com efeito, poderá ser difícil obter um resultado arm's length ante a ausência de uma transação comparável ou idêntica. É o que ocorre, geralmente, quando grupos MNE têm produção integrada de bens altamente especializados, ou quando lidam com bem intangível único.

Críticas ao legislador pátrio, no tocante aos juros, decorrem da ausência de flexibilização da norma, face ao frequente distanciamento

BRASIL. Constituição Federal, art. $145 . \S 1^{\circ}$ - "Sempre que possível, os impostos terão caráter pessoal e serão graduados segundo a capacidade econômica do contribuinte, facultado à administração tributária, especialmente para conferir efetividade a esses objetivos, identificar, respeitados os direitos individuais e nos termos da lei, o patrimônio, os rendimentos e as atividades econômicas do contribuinte". (Grifo nosso). 
entre o resultado obtido através das regras e o que de fato se verifica no mercado (arm's length). No entanto, a igualdade pode se abrir a normas de simplificação com vistas a tornar a garantir a exequibilidade da norma, como se verá a seguir.

3.3 Objeções às regras de preços de transferência sobre jurosigualdade e praticabilidade

Uma vez compreendida a sistemática brasileira de controle dos preços de transferência sobre juros, assim como o substrato valorativo do princípio da igualdade, consubstanciado na capacidade contributiva para os limites desta análise, passa-se à averiguação da constitucionalidade das normas em comento à luz do referido princípio.

A sistemática inicialmente prevista na Lei $n^{\circ}$ 9.430/96, a depender se o contribuinte brasileiro era mutuário ou mutuante, respectivamente, limitava a dedutibilidade com juros ou impunha a receita mínima pela soma da taxa LIBOR, para depósitos em dólar dos Estados Unidos da América pelo prazo de 6 meses com 3\% anuais a título de spread, proporcionalizados em função do período a que se referirem os juros. Desse modo, não havia espaço para a comparabilidade e nem para aferição dos valores praticados no referencial do mercado, o que inexoravelmente afastava o arm's length e, por decorrência, o princípio da igualdade, eivando a regra de inconstitucionalidade.

Embora o legislador tenha se mobilizado, com o advento das Leis $\mathrm{n}^{\circ}$ $12.715 / 12$ e $\mathrm{n}^{\circ} 12.766 / 12$, para superar inconstitucionalidades das regras iniciais dos preços de transferência sobre juros, os avanços editados não foram suficientes para que se possa afirmar a constitucionalidade das referidas regras de modo direto. Senão, vejamos.

A primeira questão diz com o alcance das novas regras sobre juros em matéria de preços de transferência. A supressão da salvaguarda quanto a contratos registrados no BACEN confere generalidade de aplicação às novas regras. Se antes contratos registrados no BACEN não se submetiam às normas de preços de transferência sobre juros, atualmente estão alcançados pela norma. Todavia, dúvidas surgem 
quanto ao alcance das novas regras, pois, como visto no Quadro 1, a Lei $n^{\circ} 12.766 / 12$ suprimiu do caput do art. 22 da Lei $n^{\circ}$ 9.430/96, a expressão "quando decorrentes de contrato de mútuo", que havia sido inclusa pela Lei $n^{\circ} 12.715 / 12$ pouco antes.

Pode-se entender, portanto, que as regras de preços de transferência não se aplicam apenas a operações reguladas por contratos, tampouco por somente contratos de mútuo, mas, efetivamente, a toda "remessa dos encargos de dívida de qualquer natureza cuja obrigação seja decorrente de contratos, títulos ou outras relações jurídicas" (PELÁ, 2013, p. 12).

Dúvidas aumentam quando se observa o $\S 1^{\circ}$ do artigo 22 da Lei $n^{\circ} 9.430 / 96$, que submete ao controle dos preços de transferência apenas o credor dos juros domiciliado no Brasil "no caso de mútuo com pessoa vinculada". A interpretação literal do dispositivo geraria situação desigual, pois o mutuário domiciliado no Brasil estaria sujeito ao controle dos preços de transferência em qualquer remessa de juros a pessoa vinculada. Todavia, o mutuante domiciliado no Brasil somente sofreria eventual ajuste em sua receita caso a operação vinculada decorresse de contrato de mútuo.

A IN 1312/12, com redação atualizada pela IN RFB 1322/13, trata dos juros pagos ou creditados em operações vinculadas a partir de $1^{\circ}$ de janeiro de 2013 em seu Artigo 38-A, cujo $\S 1^{\circ}$ repete a previsão legal, expressamente se referindo a "mútuo com pessoa vinculada".

Para o Código Tributário Nacional, a IN RFB caracteriza-se por norma complementar, espécie do gênero "legislação tributária", assim como a lei, que com ela não se confunde, consoante os artigos 96 e 100, I. Assim, não surpreende que o texto da IN seja cópia do que dispõe a Lei $n^{\circ} 9.430 / 96$, já que as normas complementares não podem legislar, tampouco instituir ou majorar tributo. Vinculam a Administração internamente, mas não o particular.

Elidie Bifano (2103, p.120) e João Victor Guedes Santos (2013, p.165-171) sustentam o alcance das regras de preços de transferência 
sobre juros limitados a contratos de mútuo. À luz da Constituição Federal, contudo, mais ajustado seria aplicar o controle dos preços de transferência a todas operações vinculadas em que houver pagamento ou recebimento de juros, posto que o imposto de renda deve ser informado pelo critério da generalidade, o que abrange o maior número de pessoas possível, nos termos do artigo $153, \S 2^{\circ}$, I. A generalidade é critério constitucional a ser observado para o deslinde da interpretação do caput em face do $\$ 1^{\circ}$ do artigo 22 da Lei $n^{\circ} 9.430 / 96$. Não haveria, pois, justificativa legal para entender restrito o caput em comento, posto que não faz referência apenas a contratos de mútuo, ainda que estes sejam, naturalmente, mais quantitativamente expressivos nas operações desse matiz.

Evocar a generalidade, com efeito, satisfaz ao princípio da igualdade, autêntico vetor constitucional de altíssima valoração especialmente em matéria de discriminação para imposição do ônus tributário. Demais disso, confere o mesmo tratamento legal a situações similares, in casu, remessa ou recebimento de juros em operações vinculadas, independente da formalidade que lhe serve de instrumento de efetivação, se contrato genérico, se contrato de mútuo ou outra via qualquer.

Uma segunda crítica reside no fato de que as novas regras condicionam a dedutibilidade de juros e a configuração de renda mínima a uma taxa prevista em lei a qual se acresce o spread fixado pelo Ministro da Fazenda, com base na média de mercado. De fato, o novo normativo trouxe aproximação com o mercado, mas, ainda assim, há taxas estabelecidas conforme a moeda prevista para cada obrigação, negligenciando, assim, diversas outras particularidades de cada negócio (BIFANO, 2013, p. 111). Com isso, os critérios para determinação dos parâmetros nas operações ativas e passivas indiferem, o que pode não refletir a realidade de mercado. Efeitos diversos surgem em operações internacionais, mormente por conta dos riscos atribuídos aos devedores e respectivos riscos conjunturais das jurisdições em que residem. Logo, um contrato em que o devedor esteja no Brasil e o credor no estrangeiro poderá praticar juros mais altos que o inverso. Distinções dessa natureza 
não foram contempladas pela nova sistemática (SANTOS, 2013, p. 184). Em nosso ver, a dificuldade aqui não reside no fato de haver limites determinados pela soma da taxa e do spread, mas de serem inflexíveis, pois poderá haver situações em que a remessa/recebimento de juros reflita condições especialíssimas de mercado que serão desprezadas.

Do mesmo modo, a extensão da aplicação das regras às operações realizadas com pessoa estabelecida em países com tributação favorecida ou regime especial privilegiado, ainda que sem qualquer vínculo dessas pessoas com o contribuinte nacional, também ofende aos princípios da igualdade e da capacidade contributiva (ALMEIDA, 2014, p. 310).

Em terceiro lugar, deve-se ter em mente que o poder conferido ao Ministro da Fazenda na determinação do spread (que, juntamente com as taxas definidas pelo parágrafo $6^{\circ}$ representarão o percentual limite para os juros praticados) não pode ser visto como discricionário. Contrario sensu teria a regra brasileira atribuída ao Executivo o poder de majorar e reduzir o imposto sobre a renda através da manipulação do spread estabelecido para as operações com juros sujeitas às regras de preços de transferência.

Não se trata, pois, de ato meramente discricionário, visto que os critérios a serem utilizados na determinação dessa margem estão previstos em lei. O ato praticado pelo Ministro da Fazenda deve, portanto, observar, rigorosamente, a "média de mercado", que pode ser obtida, por exemplo, através do semanal Relatório Focus do Banco Central, ou por meio de outros indicadores publicados pelo BACEN (SCHOUERI, 2013, p. 350).

Embora já se previsse do mesmo modo antes das alterações efetuadas pelo legislador, aplicar ajustes de preços de transferência a operações realizadas com pessoa domiciliada em países com tributação favorecida ou regime especial privilegiado sem vínculo com residente no Brasil afasta o arm's length e, por via de consequência, a capacidade contributiva e a igualdade. Sobreleva-se, aqui, a presunção de que operações com pessoas domiciliadas em paraísos fiscais podem sofrer 
ajustes, ainda que tenham sido praticadas em conformidade com as regras do mercado aberto e com independência das partes.

Em síntese, condicionar a dedutibilidade/receita mínima dos juros à revelia da realidade das operações não franqueia a oportunidade de quebra dessas margens pelo contribuinte, que poderia questionar percentuais impostos caso observasse o arm's length. O fato de os ajustes não representarem os percentuais que seriam praticados no mercado, em operações similares entre pessoas não vinculadas, fere a igualdade, eivando de inconstitucionalidade a norma.

Contudo, a concretização de valores dificilmente se dará de forma absoluta e outros valores constitucionalmente preconizados podem ser evocados a sopesar a igualdade. Assim ocorre, por exemplo, com a praticabilidade. Cada concessão a esta última é um sacrifício suportado pela primeira (SCHOUERI, 2013, p. 24).

Nesta esteira, o legislador brasileiro, ao mesmo tempo em que efetivou o princípio arm's length de forma implícita, reconheceu, em vista dos complexos e custosos procedimentos para respeitar a comparabilidade em operações internacionais, a necessidade da observância da praticabilidade, encontrando, para tanto, o necessário respaldo constitucional (GREGÓRIO, 2011, p. 27).

Não por outra razão que a busca pelo arm's length, comumente apregoada por membros da OCDE, encontra, no ordenamento brasileiro, um contraponto de simplificação nominado praticabilidade. Justificável, pois, a mitigação do arm's length, em razão da impossibilidade de atuação individualizada da administração tributária diante da singular complexidade econômica contemporânea, por razões de ordem prática.

A praticabilidade consagra a busca do legislador para evitar arbitrariedades na aplicação do Direito, preservando justiça e igualdade. Destarte, a aplicação da praticabilidade pode resultar em tratamento distinto a situações equivalentes, mas o ganho gerado pela simplificação 
trazida pela praticabilidade somente atenderá à Constituição se não for desproporcional ou irrazoável. ${ }^{8}$

Assim, o princípio arm's length foi adotado pela legislação nacional como norteador das regras de preço de transferência, mas pode ter mitigados seus efeitos ante normas de simplificação que atendam à praticabilidade desde que não firam, além do desejável, a igualdade no caso concreto. Neste caso, deve-se entender que a aferição exata dos contornos da capacidade contributiva, mormente em complexas relações internacionais, exigiria da Administração algo superior às suas próprias forças.

Há quem defenda a praticabilidade na condição de desdobramento do princípio da supremacia do interesse público sobre o particular (princípio da finalidade pública ou do interesse coletivo), essencial ao Estado na consecução de seus fins, como, in casu, a devida arrecadação dos tributos (COSTA, 2007, p. 93).

Sob ângulo distinto, há quem tome a praticabilidade em íntima relação com a igualdade, auxiliando sua concretização por permitir a execução efetiva da norma em vista de seu efeito generalizante. Uma norma cuja execução seja impossível, ainda que prescreva igualdade, não produzirá efeitos igualitários. Destarte, a Constituição implicitamente autoriza o uso da praticabilidade, por meio do qual a norma atinge maior generalização e, consequentemente, maior eficácia (ZILVETI, 2004, p. 315).

Em matéria de preços de transferência sobre juros, as críticas residem na excessiva importância atribuída pelo legislador à simplificação em detrimento de outros valores como a capacidade contributiva, corolário da igualdade (GREGÓRIO, 2011, p. 27). É verdade, porém, que

Proporcionalidade é medida concreta para atingir determinado fim sob os crivos de adequação, necessidade e proporcionalidade stricto sensu. A aprovação nesses três testes atesta conformidade à ordem constitucional vigente. Já a razoabilidade, estruturadora da aplicação de princípios e regras, atua sob diferentes formas, especialmente equidade, congruência, equivalência e coerência. 
a praticabilidade representa, a priori, argumento legítimo em favor da constitucionalidade das normas brasileiras de preços de transferência, mas para servir à igualdade, melhor será admitir que o contribuinte faça prova em contrário da renda disponível - presunção juris tantum (ZILVETI, 2004, p. 320).

Percebe-se que as atuais regras brasileiras sobre preço de transferência sobre juros são resultado da construção de um modelo único, decorrente da ponderação de diversos valores e critérios constitucionalmente previstos para a tributação da renda. Consequentemente, é necessário empreender uma análise casuística, considerando proporcionalidade e razoabilidade, para que se possa concluir acerca da constitucionalidade de um embate entre igualdade e praticabilidade.

\section{Conclusão}

As regras de preço de transferência buscam, pela aplicação do arm's length, que encontra seu equivalente no princípio da igualdade, garantir que as transações realizadas entre partes vinculadas tenham uma tributação conforme a justiça. Aqui reside a justificativa da observância da capacidade contributiva, corolário direto da igualdade.

Para atingir seu desiderato, o legislador prescreveu diferentes métodos que aproximassem operações entre vinculadas com operações independentes, realizadas entre pessoas não vinculadas, desde que houvesse a necessária comparabilidade entre elas. Esta comparabilidade entre operações de natureza distinta mostra-se fundamental para efetivação do princípio da igualdade em direito tributário, pela imposição de uma mesma carga tributária a pessoas em situações equivalentes. Assim, embora implícito, vige o arm's length no ordenamento brasileiro.

Contudo, atento às predisposições constitucionais e preocupado com eventuais efeitos que normas mais flexíveis poderiam trazer ao ordenamento jurídico, optou o legislador, em determinados momentos, por efetivar a praticabilidade, em contraponto ao arm's length. É o 
que ocorre com relação às regras para controle fiscal dos preços de transferência sobre juros.

Na prática, normas de simplificação ganham contorno em rígidas margens prefixadas, que acabam por ignorar a complexidade das operações e afastá-las da realidade dos preços que seriam, efetivamente, praticados entre partes independentes. Se por um lado, tal sistemática prestigia a praticabilidade e, inclusive, viabiliza a fixação de parâmetros para operações singulares, sem similar no mercado; por outro, ao deixar de colocar operações em uma mesma unidade de referência, inviabiliza a efetiva comparação entre elas. Consequentemente, seus ajustes podem resultar em tributação de valores que não refletem o conceito de renda, exacerbando a hipótese de incidência do imposto e ferindo a igualdade.

A OCDE, ciente dessa limitação, tolera a aplicação de outros métodos, desde que evidenciado o respeito ao arm's length, caso os métodos por ela sugeridos se afastem das práticas reais de mercado. No Brasil, há uma pequena abertura ao contribuinte sujeito às regras de preço de transferência para postular, administrativamente, pela aplicação de outras margens não previstas em lei, mas essa possibilidade não se estende à matéria dos juros.

Logo, apesar da maior aproximação com o mercado por meio da ampliação das hipóteses e taxas trazidas pelas recentes mudanças na legislação, lícito concluir que, quanto à disciplina dos preços de transferência sobre juros, a preocupação com a praticabilidade prevaleceu na determinação do modelo brasileiro, em detrimento dos princípios da igualdade e da capacidade contributiva.

\section{Referências}

ALMEIDA, Carlos Otávio Ferreira de. O modelo brasileiro do arm's length sob a óptica da teoria da justiça. Revista direito tributário, São Paulo, n. 23,2009, p. 103-118. 
ALMEIDA, Carlos Otávio Ferreira de. Tributação internacional da renda: a competitividade brasileira à luz das ordens tributária e econômica. São Paulo: Quartier Latin, 2014. (Série Doutrina Tributária, v. XIII).

ÁVILA, Humberto. Teoria dos princípios: da definição à aplicação dos princípios jurídicos. 10. ed. São Paulo: Malheiros Editores, 2009.

BASTIN, Lucas. Transfer pricing and the WTO. Journal of world trade, Amsterdã, v.48.WoltersKluwer Law \& Business, 2014, p.59-80.

BIFANO, Elidie Palma. Disciplina dos juros em matéria de preços de transferência. In: SCHOUERI, Luís Eduardo (Coord.) Tributos e preços de transferência, São Paulo: Dialética, 2013, p. 104-124. v. 4.

BRASIL. Constituição da República Federativa do Brasil de 1988. Disponível em: <http://www.planalto.gov.br/ccivil_03/constituicao/ ConstituicaoCompilado.htm>. Acesso em: 30 jun. 2015

BRASIL. Exposição de Motivos n 470, de 15 de Outubro de 1996. Diário da Câmara dos Deputados, ano LI, n²14. Brasília, DF, 19 de novembro de 1996. Disponível em: <http://imagem.camara.gov.br/lmagem/d/pdf/ DCD19NOV1996.pdf\#page=43>. Acesso em: 02 ago. 2014.

BRASIL. Lei $n^{\circ}$ 9.430, de 27 de dezembro de 1996. Dispõe sobre a legislação tributária federal, as contribuições para a seguridade social, o processo administrativo de consulta e dá outras providências. Diário Oficial da União, Brasília, DF, 27 de dezembro de 1996. Disponível em: <http://www.planalto.gov.br/ccivil_03/leis/l9430.htm>. Acesso em: 17 jul. 2014

BRASIL. Ministério da Fazenda. Instrução Normativa RFB n 1.312 , de 28 de dezembro de 2012. Dispõe sobre os preços a serem praticados nas operações de compra e de venda de bens, serviços ou direitos, efetuadas por pessoa física ou jurídica residente ou domiciliada no Brasil, com pessoa física ou jurídica residente ou domiciliada no exterior, consideradas vinculadas. Diário Oficial da União, Brasília, DF, 31 de dezembro de 2012. Disponível em: <http://www.receita.fazenda.gov.br/ Legislacao/ins/2012/in13122012.htm>. Acesso em: 04 ago. 2014 
BRASIL. Ministério da Fazenda. Instrução Normativa RFB n 1.322, de 16 de janeiro de 2013. Altera a Instrução Normativa RFB $n^{0} 1.312$, de 28 de dezembro de 2012, que dispõe sobre os preços a serem praticados nas operações de compra e de venda de bens, serviços ou direitos efetuadas por pessoa física ou jurídica residente ou domiciliada no Brasil, com pessoa física ou jurídica residente ou domiciliada no exterior, consideradas vinculadas. Diário Oficial da União, Brasília, DF, 18 de janeiro de 2013. Disponível em: <http://www.receita.fazenda.gov. br/legislacao/ins/2013/in13222013.htm>. Acesso em: 02 ago. 2014

COSTA. Regina Helena. Praticabilidade e justiça tributária: exeqüibilidade da lei tributária e direitos do contribuinte. São Paulo: Malheiros, 2007.

CURTY, Leonardo de Menezes. O sistema brasileiro de controle de preços de transferência à distância de um braço. In: MARIZ DE OLIVEIRA, R.; SCHOUERI, L.E. e ZILVETI, F. A. (Coord.). Revista direito tributário atual 29, São Paulo, 2013, p. 222-236.

GREGORIO, Ricardo Marozzi. Preços de transferência: arm's length e praticabilidade. São Paulo: Quartier Latin, 2011. (Série Doutrina Tributária v. V.).

HIGUCHI, Hiromi. Imposto de renda das empresas. 37. ed. São Paulo: IR Publicações, 2012.

HORTA, Nereida de Miranda Finamore. Reflexões acerca das regras de preço de transferência aplicáveis a juros. In: SCHOUERI, Luís Eduardo (Coord.). Tributos e preços de transferência. São Paulo: Dialética, 2013. p. 283-295. v. 4.

MARCONI, Marina de Andrade. Metodologia científica para o curso de direito. 2. ed. São Paulo: Atlas, 2001.

MINISTÉRIO DA FAZENDA. Portaria MF $n^{\circ} 222$, de 24 de setembro de 2008. Dispõe sobre os percentuais e margens de lucros a serem aplicados na determinação de preços a serem utilizados como parâmetro nas operações de compra e venda de bens, serviços e direitos, efetuadas por pessoa física ou jurídica, residente ou domiciliada no Brasil, com pessoa física ou jurídica vinculada, domiciliada no exterior. Diário 
Oficial da União, Brasília, DF, 26 de setembro de 2008. Disponível em: <http://www.receita.fazenda.gov.br/Legislacao/Portarias/2008/ MinisteriodaFazenda/portmf222.htm>. Acesso em: 17 jul. 2014

MINISTÉRIO DA FAZENDA. Portaria n 427, de 30 de julho de 2013. Dispõe sobre a dedutibilidade e o reconhecimento de receita financeira de juros, em operações com pessoas vinculadas, para fins de apuração do lucro real, conforme as regras de preços de transferência. Diário Oficial da União, Brasília, DF, 02 de agosto de 2013. Disponível em: <http://www.fazenda.gov.br/institucional/legislacao/2013/portaria-no.427-de-30-de-julho-de-2013>. Acesso em: 17 jul. 2014

Organisation for Economic Co-operation and Development -OCDE. Transfer pricing guidelines for multinational enterprises and tax administrations. Paris: OCDE, 2009.

Organisation for Economic Co-operation and DeVelopment - OCDE. Income and capital model convention and commentary. Paris: OCDE, 2014. Disponível em: <ip-online.ibfd.org/collections/ttmodel/ printversion/tt_o2_02_eng_2014_mo.html>.

PELÁ, Carlos. Juros e preços de transferência: nova sistemática introduzida pela Lei n. 12.766/2012. In: SCHOUERI, Luís Eduardo (Coord.), Tributos e preços de transferência. São Paulo: Dialética, 2013, p. 7-28. v. 4.

RODRIGUEZ, Marcelo Natale. Nova disciplina de preços de transferência sobre Juros. In: SCHOUERI, Luís Eduardo (Coord.). Tributos e preços de transferência. São Paulo: Dialética, 2013. p. 228-242. v. 4.

SANTOS, João Victor Guedes. Juros e preços de transferência: a necessária reforma da legislação reformada. In: SCHOUERI, Luís Eduardo (Coord.). Tributos e preços de transferência. São Paulo: Dialética, 2013. p. 163-188. v. 4.

SCHOUERI, Luis Eduardo. Preços de transferência no direito tributário brasileiro. 3. ed. rev. e atu. São Paulo: Dialética, 2013. 
TORRES, Ricardo Lobo. Tratado de direito constitucional financeiro e tributário: os direitos humanos e a tributação: imunidades e isonomia. Rio de Janeiro: Renovar, 1999. v. 3.

WEEGHEL, Stef Van; EMMERINK, Frank. Global developments and trends in international anti-avoidance. Bulletin for international taxation, Amsterdam, v. 67, n. 8, p. 428-435, 2013.

ZILVETI, Fernando Aurélio. Princípios de direito tributário e a capacidade contributiva. São Paulo: Quartier Latin, 2004.

Recebido em: 19/04/2015

Aprovado em: 30/11/2015 